Journal of Patient-Centered

\title{
Medically Tailored Meals as a Prescription for Treatment of Food- Insecure Type 2 Diabetics
}

Leslie J. Rabaut

Follow this and additional works at: https://aah.org/jpcrr

Part of the Community Health and Preventive Medicine Commons, Dietetics and Clinical Nutrition Commons, Endocrine System Diseases Commons, Endocrinology, Diabetes, and Metabolism Commons, and the Public Health Education and Promotion Commons

\section{Recommended Citation}

Rabaut LJ. Medically tailored meals as a prescription for treatment of food-insecure type 2 diabetics. J Patient Cent Res Rev. 2019;6:179-83. doi: 10.17294/2330-0698.1693

Published quarterly by Midwest-based health system Advocate Aurora Health and indexed in PubMed Central, the Journal of Patient-Centered Research and Reviews (JPCRR) is an open access, peer-reviewed medical journal focused on disseminating scholarly works devoted to improving patient-centered care practices, health outcomes, and the patient experience. 


\title{
Medically Tailored Meals as a Prescription for Treatment of Food-Insecure Type 2 Diabetics
}

\author{
Leslie J. Rabaut, DO \\ Aurora Family Medicine Residency Program, Aurora Health Care, Milwaukee, WI
}

\begin{abstract}
Type 2 diabetes mellitus is an immense burden to the health of our population and to our current health care system, and the weight of this burden is only projected to multiply in coming years. A nutritious diet is an indispensable aspect of diabetes treatment, and the lack of access to food engenders poor disease-state control, which correlates with increased health care utilization. Interventions aimed at improving access to food through medically tailored meals (MTMs) have demonstrated effectiveness in improving the health of food-insecure type 2 diabetic patients and reducing health care costs. Further studies are necessary to increase the external validity of existing positive research on medically tailored meals in food-insecure diabetic patients and to provide evidence to support potential policy changes under which the costs of medically tailored meals for diabetics might be covered by insurers. (J Patient Cent Res Rev. 2019;6:179-183.)
\end{abstract}

Keywords diabetes mellitus; public health; diet; nutrition; food security; meals; health care costs

\section{What Is 'Food Insecurity'?}

A nutritious diet is an indispensable aspect of diabetes treatment. ${ }^{1-3}$ The lack of reliable access to food engenders poor disease-state control $^{2,4-7}$ and correlates with increased utilization of costly health care services. ${ }^{5,8-12}$ In 2016, an estimated $14.3 \%$ of the general American population was food insecure as compared to $21 \%$ of the diabetic population. ${ }^{9}$

Food insecurity (FI) is defined as "limited or uncertain availability of nutritionally adequate and safe foods or ability to acquire food in socially acceptable ways." "13 Food security encompasses not only economic factors. ${ }^{2,14}$ Residing in a food desert, or an area with limited access to nutritious food, ${ }^{15}$ reduces food security. Additional determining factors include the safety of the environment, transportation, work schedules, time, and familiarity with preparing

Correspondence: Leslie J. Rabaut, DO,

Aurora Family Medicine Residency, 2801 W. Kinnickinnic

River Parkway, \#250, Milwaukee, WI, 53215

(leslie.rabaut@aurora.org) foods. ${ }^{2,14}$ Factors that predict a high level of FI include poverty, low level of education, single-mother household, and ethnic minority. ${ }^{8}$

FI can be measured by either the 18-item U.S. Household Food Security Survey or the shorter and more practical 2-item Hunger Vital Sign. The Hunger Vital Sign asks the frequency with which 1) "we worried whether our food would run out before we got money to buy more," and 2) "the food we bought just didn't last and we didn't have money to get more." This tool has been validated in all ages and shown to have a high sensitivity and specificity for identifying food-insecure individuals. ${ }^{16}$

Screening for FI is important because FI is prevalent, it often goes undiagnosed, and there are interventions that can be taken to increase food access if the condition is identified. ${ }^{4,16}$

\section{How Does FI Influence the Health of a Type 2} Diabetic?

Perhaps the most important environmental and modifiable risk factor for type 2 diabetes (DM2) is a patient's diet. ${ }^{1-3}$ Diabetic patients benefit from a diet 
that prioritizes vegetables, whole grains, low-glycemicindex foods, dairy, legumes, and nuts while minimizing intake of processed red meats, sugary foods, and refined grains. ${ }^{1,2}$ A recent meta-analysis of studies of diets and DM2 demonstrated a directly linear relationship between consumption of red meats, processed meats, and sweetened beverages and risk of DM2. There was an inverse association of DM2 risk with intake of whole grains, vegetables, and fruits. ${ }^{3}$ Dietary changes, both in quality and caloric quantity, have proven powerful enough to cause diabetes remission and decreased diabetes complications. ${ }^{1}$ Not surprisingly, type 2 diabetics are especially vulnerable to FI.,

FI is independently associated with diabetes - foodinsecure patients are at up to twice the risk for diabetes ${ }^{4,5}$ - and the prevalence of diabetes increases as the degree of FI increases, with the highest prevalence among the least secure. ${ }^{5,6}$ In a 10-year cross-sectional study of National Health and Nutrition Examination Survey data, almost one-quarter of 2.1 million diabetics with uncontrolled A1c levels were food insecure. ${ }^{7}$

In a study of California's population, the odds of diabetes were $120 \%$ greater in patients who lacked food security, even after accounting for other variables (exercise, weight, and demographics). ${ }^{9}$ Scientists are even starting to question which came first the diabetes or the FI? Evidence now suggests that nutritional deprivation or malnutrition of pregnant mothers can actually predispose the developing fetus in utero to epigenetic changes that result in an increased risk for impaired glucose metabolism and diabetes as an adult. ${ }^{17,18}$ Beyond these risk factors, food-insecure diabetic patients are more likely to have poorer glycemic control, ${ }^{2,4-6}$ and FI has been shown in multiple studies to be independently associated with elevated hemoglobin A1c levels., ${ }^{2,7}$

The mechanisms by which FI increases the risk of diabetes and the propensity for it to be uncontrolled are multifaceted. ${ }^{1,2,4-6,10,11,19-21}$ Firstly, vegetables and fruits simply cost more than refined fats and sugary foods. ${ }^{1,4,6}$ For example, between 1985 and 2000 the cost of sugary sweetened beverages rose by $20 \%$, sweets by $46 \%$, and fresh fruits and vegetables by $118 \% .{ }^{6}$ Thus, the diabetic diet can be inherently costprohibitive for low-income families ${ }^{1,4,6}$ Consequently, food-insecure patients often resort to the cheapest food items available, which tend to be the exact opposite of the preferred diabetic diet, wreaking havoc on their blood sugars and diabetes control., ${ }^{4,610,22}$

Secondly, food-insecure persons may reside in food deserts and simply do not have geographically accessible nutritious food. ${ }^{2}$ Whether food is not accessible due to cost or geography, the lack of a reliable diet inherently provokes additional maladaptive behaviors that further complicate the regulation of blood sugars. ${ }^{4-6}$ Foodinsecure patients may binge when food is prevalent or skip meals when food is scarce. ${ }^{4-6}$ Such eating patterns may contribute to the development of insulin resistance, 5,6 the primary pathology of diabetes.

Not only does FI lead to skipping meals but also to skipping medical care. For monetary reasons, foodinsecure persons are often forced to choose between medications and food ${ }^{4,6,20}$ or to postpone health care visits. ${ }^{5,6,11,19}$ These patients have decreased ability to perform self-care management with medication use and glucose monitoring ${ }^{21,23}$ and are at twice the risk of dangerous hypoglycemic events. . $^{2,4,6,9}$

All of the aforementioned factors likely contribute to higher reports of depression, decreased self-efficacy, and increased diabetes distress among food-insecure patients. ${ }^{20,21}$

\section{Effect of FI on the Health Care System}

Not only is FI associated with increased prevalence of diabetes and poor diabetes control, but it is also associated with increasing health care expenditures due to increased numbers of costly emergency department visits, inpatient hospitalizations, and prescription medications..$^{5,8-12,19} \mathrm{FI}$ is associated with $\$ 77$ billion in excess health care expenditures annually. ${ }^{24}$ Diabetics with low food security and self-efficacy have been demonstrated to have more than twice the health care utilization of their food-secure counterparts. ${ }^{9}$ Specifically, these patients have increased utilization of acute care, ${ }^{19}$ often presenting to the emergency department with hypoglycemic events necessitating hospitalization. ${ }^{10,19}$ Interestingly, this increased use of acute care has not been demonstrated to be mitigated by maintaining regular ambulatory care visits. ${ }^{19}$ The increased propensity for hospitalization has costly implications when taking into account the fact that $30 \%$ of total medical costs of DM2 is derived from 
hospitalizations. The national cost of diabetes in 2017 was estimated at $\$ 327$ billion. ${ }^{25}$

Even after being stabilized in the hospital, food-insecure patients have double the likelihood of being readmitted within 15 days of discharge. ${ }^{26}$ This fact should give all health care systems pause in a world in which hospitals are reimbursed significantly less for "excessive readmissions" of Medicare and Medicaid patients under the Affordable Care Act. ${ }^{27}$ In light of these costs and the immense rise and projected continued growth in diabetes prevalence - the number of patients with diabetes globally has more than doubled over the past 3 decades, and prevalence is expected to rise to almost 440 million by $2030^{17}$ - it becomes clear that novel, more effective, and cost-reducing treatment options of diabetes are needed..$^{9,17}$

\section{Current Programs to Address FI Are Not Adequate}

Currently the health care system does not directly address FI, ${ }^{16,18}$ and existing resources aimed at addressing the issue of FI are either not nutritionally appropriate, not robust enough in size, or not reliably reproducible. ${ }^{14,18,21,22,24}$

The largest governmental safety net for the food insecure is the Supplemental Nutrition Assistance Program (SNAP), which was created in the 1960s and has failed to adjust its dietary offerings as the dietary practices of Americans have become increasingly unhealthy. The control of SNAP has shifted from the federal government to retailers, the food service industry, and manufacturers who do not have the health of recipients in mind and continue to lobby against any SNAP restrictions on refined carbohydrates, fats, and sugary sweetened beverages. ${ }^{22}$ SNAP recipients today eat a very unhealthful diet, the antithesis of the diabetic diet. ${ }^{22}$ What's more, only the most severely impoverished persons qualify for SNAP benefits, thus a significant proportion of food-insecure patients who do not meet the levels of poverty necessary to qualify for SNAP remain without any governmental supports. ${ }^{8,10,21,22}$

Outside of governmental resources, some health care systems offer clinic-community models in which clinics provide food vouchers and refer patients to local food pantries. ${ }^{18}$ The success of these programs is dependent on the unique resources available in a particular area (and thus not easily generalizable), and these programs require a lot of active work on the part of the patient to seek out local food suppliers, to choose the "correct" foods, and to prepare those foods at home on a consistent basis. ${ }^{18}$ This model does not account for other aspects that contribute to FI, including lack of transportation, environment, personal stressors such as work and time availability, and lack of familiarity with choosing and preparing nutritious foods..$^{2,14,18}$

\section{Role of Medically Tailored Meals in Addressing FI in Diabetic Patients}

One intervention demonstrated to be successful in decreasing FI, improving health, and cutting costs is medically tailored meal (MTM) programs. ${ }^{11,21,24,28,29}$ MTMs are designed by a nutritionist to meet the particular nutritional needs of patients according to their disease states. ${ }^{24,29} \mathrm{~A}$ population that has benefited from meal delivery programs since the 1950s - and, consequently, is the most studied is homebound seniors receiving Meals on Wheels. Seniors receiving Meals on Wheels receive standard but consistent meals with resulting improved dietary intake, decreased rates of depression and loneliness, and higher quality of life. ${ }^{11,28}$ They have improved measures for activities of daily living, significant reductions in hospital readmission rates, ${ }^{11,28}$ and are less likely to be admitted to a nursing home. ${ }^{30}$

Recent studies have demonstrated a greater potential of meal delivery programs to improve health and cut costs when those meals are medically tailored to patients' disease states. ${ }^{21,24,29}$ A 2013 study by Gurvey et al that provided MTMs over a 6-month period to nutritionally at-risk, chronically ill patients, one-quarter of whom had diabetes, resulted in impressive outcomes. In the intervention group, the number of hospital admissions decreased by $50 \%$, hospitalizations were $37 \%$ shorter in length, and patients were more than $20 \%$ more likely to be discharged to home as opposed to an expensive nursing facility. The overall average monthly cost per patient decreased by $55 \% .{ }^{29}$

A more recent (2018) study of MTMs published in Health Affairs demonstrated similarly promising results. ${ }^{24}$ In this study, MTMs were provided over 
a 6-month period to chronically ill, dually eligible Medicaid/Medicare patients, resulting in substantial statistically significant reduction in health care utilization and costs. The study reported decreased number of emergency department visits, inpatient hospitalizations, and ambulance usage among persons who received delivery of MTMs in comparison to matched persons who did not receive meals. What's more, the program saved the health care system money, with an estimated monthly net savings of $>\$ 200$ per person in the meal program. ${ }^{24}$

Finally, a 2017 study in San Francisco demonstrated the beneficial aspects of MTMs specifically for the food-insecure diabetic population in the realms of mental, physical, and behavioral health. ${ }^{21}$ Over a 6-month period, 53 diabetic patients with incomes less than $300 \%$ of federal poverty level were provided weekly MTMs based on a Mediterranean diet in line with American Diabetic Association guidelines. Patients picked meals up from a distributing location twice weekly, and meals provided $100 \%$ of daily energy requirements. The result was a statistically significant improvement in individual health. Patients reported improved diets, with decreased consumption of fats and sugars and increased consumption of fresh fruits and vegetables. Patients also had significantly improved confidence, with decreased diabetes distress and improved perceived self-management of their diabetes. Finally, patients reported decreased depressive symptoms, binge drinking, and the sacrificing of health care or prescriptions for food. Patients had decreased body mass index, A1c levels, emergency department visits, and hospitalizations; however, this study was not sufficiently powered to demonstrate statistical significance of those changes. Perhaps most fascinating is the fact that the cost per patient per 6 months was $\$ 1184$; in comparison the cost of 1 day in a California hospital was estimated to be $\$ 2774 .{ }^{21}$

\section{Conclusions}

Diabetes is a prevalent and immense burden to the health care system, and food insecurity increases this burden through decreased glycemic control and increased health care utilization. Nutrition is an essential aspect of diabetes management, and access of food-insecure patients to appropriate meals is an indispensable aspect of diabetes treatment. Recent studies have demonstrated medically tailored meals to be an effective treatment intervention in both improving health and decreasing health care costs. Future studies are needed to further elucidate the impact of MTMs on health and costs of the diabetic population, specifically. Additional positive data might support the potential reimbursement of MTMs in the health care setting by private insurers and Medicare/Medicaid. The current health care system is increasingly cost-conscious and quality-oriented, and health care systems and insurers must seek out novel treatment options such as MTMs to meet these goals.

\section{Patient-Friendly Recap}

- Inadequate access to food results in poor nutritional status, with diabetic patients more vulnerable to the negative effects of an unhealthy diet.

- Medically tailored meals have been shown to improve health outcomes in specific patient populations (eg, seniors, chronically ill) as well as reduce care costs.

- The author's review of available evidence suggests further research on the potential benefits of prescribing (and insuring) medically tailored meals for patients with type 2 diabetes is warranted.

\section{Conflicts of Interest}

None.

\section{References}

1. Forouhi NG, Misra A, Mohan V, Taylor R, Yancy W. Dietary and nutritional approaches for prevention and management of type 2 diabetes. BMJ. 2018;361:k2234. CrossRef

2. Shalowitz MU, Eng JS, McKinney CO, et al. Food security is related to adult type 2 diabetes control over time in a United States safety net primary care clinic population. Nutr Diabetes. 2017;7(5):e277. CrossRef

3. Schwingshakl L, Hoffmann G, Lampousi A, et al. Food groups and risk of type 2 diabetes mellitus: a systematic review and meta-analysis of prospective studies. Eur $J$ Epidemiol. 2017;32:363-75. CrossRef

4. Seligman HK, Jacobs EA, López A, Tschann J, Fernandez A. Food insecurity and glycemic control among low-income patients with type 2 diabetes. Diabetes Care. 2012;35:233-8. CrossRef

5. Seligman H, Bindman AB, Vittinghoff E, Kanaya AM, Kushel MB. Food insecurity is associated with diabetes mellitus: results from the National Health Examination and Nutrition Examination Survey (NHANES) 1999-2002. J Gen Intern Med. 2007;22:1018-23. CrossRef 
6. Seligman HK, Schillinger D. Hunger and socioeconomic disparities in chronic disease. $N$ Engl J Med. 2010;363:6-9. CrossRef

7. Berkowitz SA, Baggett TP, Wexler DJ, Huskey KW, Wee CC. Food insecurity and metabolic control among U.S. adults with diabetes. Diabetes Care. 2013;36:3093-9. CrossRef

8. Gundersen C, Ziliak JP. Food insecurity and health outcomes. Health Aff (Millwood). 2015;34:1830-9. CrossRef

9. Becerra MB, Allen NL, Becerra BJ. Food insecurity and low self-efficacy are associated with increased healthcare utilization among adults with type II diabetes mellitus. $J$ Diabetes Complications. 2016;30:1488-93. CrossRef

10. Berkowitz SA, Basu S, Meigs JB, Seligman HK. Food insecurity and health care expenditures in the United States, 2011-2013. Health Serv Res. 2018;53:1600-20. CrossRef

11. Wright L, Vance L, Sudduth C, Epps JB. The impact of a home-delivered meal program on nutritional risk, dietary intake, loneliness, and social well-being. J Nutr Gerontol Geriatr. 2015;34:218-27. CrossRef

12. Tarasuk V, Cheng J, de Oliveira C, Dachner N, Gundersen C, Kurdyak P. Association between household food insecurity and annual health care costs. CMAJ. 2015;187:E429-E436. CrossRef

13. Anderson SA (ed). Core indicators of nutritional state for difficult-to-sample populations. J Nutr. 1990;120 Suppl 11:1559-600. CrossRef

14. Walker RE, Keane CR, Burke JG. Disparities and access to healthy food in the United States: a review of food deserts literature. Health Place. 2010;16:876-84. CrossRef

15. Ver Ploeg M, Breneman V, Farrigan $\mathrm{T}$, et al. Access to Affordable and Nutritious Food: Measuring and Understanding Food Deserts and Their Consequences. Report to Congress. Administrative Publication No. (AP-036). https://www.ers.usda.gov/publications/pubdetails/?pubid=42729. Washington, DC: U.S. Department of Agriculture Economic Research Service, 2009, pp. 1-160. Accessed February 27, 2019.

16. Cutts D, Cook J. Screening for food insecurity: short-term alleviation and long-term prevention. Am J Public Health. 2017; 107:1699-700. CrossRef

17. Chen L, Magliano DJ, Zimmet PZ. The worldwide epidemiology of type 2 diabetes mellitus - present and future perspectives. Nat Rev Endocrinol. 2011;8:228-36. CrossRef

18. Barnidge, E, Stenmark S, Seligman H. Clinic-to-community models to address food insecurity. JAMA Pediatr. 2017;171:507-8. CrossRef

19. Kushel MB, Gupta R, Gee L, Haas JS. Housing instability and food insecurity as barriers to health care among low-income Americans. J Gen Intern Med. 2006;21:71-7. CrossRef
20. Sattler EL, Lee JS, Bhargava V. Food insecurity and medication adherence in low-income older Medicare beneficiaries with type 2 diabetes. J Nutr Gerontol Geriatr. 2014;33:401-17. CrossRef

21. Palar K, Napoles T, Hufstedler LL, et al. Comprehensive and medically appropriate food support is associated with improved HIV and diabetes health. J Urban Health. 2017;94:87-99. CrossRef

22. Popkin BM. The challenge in improving the diets of supplemental nutrition assistance program recipients: a historical commentary. Am J Prev Med. 2017;52:S106-S114. CrossRef

23. Ippolito M, Lyles CR, Prendergast $\mathrm{K}$, Marshall MB, Waxman E, Seligman HK. Food insecurity and diabetes selfmanagement among food pantry clients. Public Health Nutr. 2017;20:183-9. CrossRef

24. Berkowitz SA, Terranova J, Hill C, et al. Meal delivery programs reduced the use of costly health care in dually eligible Medicare and Medicaid beneficiaries. Health Aff (Millwood). 2018;37:535-42. CrossRef

25. American Diabetes Association. The cost of diabetes. Last reviewed 2018 Apr 24. http://www.diabetes.org/advocacy/ news-events/cost-of-diabetes.html. Accessed May 5, 2018.

26. Ellwood M, Downer S, Leib EB, et al. Food Is Medicine: Opportunities in Public and Private Health Care for Supporting Nutritional Counseling and Medically-Tailored, Home-Delivered Meals. Cambridge, MA: Center for Health Law \& Policy Innovation, Harvard Law School, 2014, pp. $1-51$.

27. Centers for Medicare \& Medicaid Services. Hospital Readmissions Reduction Program (HRRP). Last modified 2019 Jan 16. https://www.cms.gov/medicare/medicarefee-for-service-payment/acuteinpatientpps/readmissionsreduction-program.html. Accessed March 1, 2019.

28. Campbell AD, Godfryd A, Buys DR, Locher JL. Does participation in home-delivered meals programs improve outcomes for older adults? Results of a systematic review. $J$ Nutr Gerontol Geriatr. 2015;34:124-67. CrossRef

29. Gurvey J, Rand K, Daugherty S, Dinger C, Schmeling J, Laverty N. Examining health care costs among MANNA clients and a comparison group. J Prim Care Community Health. 2013;4:311-7. CrossRef

30. Thomas KS, Mor V. Providing more home-delivered meals is one way to keep older adults with low care needs out of nursing homes. Health Aff (Millwood). 2013;32:1796-802. CrossRef

(C) 2019 Aurora Health Care, Inc. 